\title{
EFEITO DO SILICATO DE CÁLCIO E DA AUTOCLAVAGEM NA SUPRESSIVIDADE E NA CONDUCIVIDADE DE DOIS SOLOS À RHIZOCTONIA SOLAN/'
}

\author{
FABRÍCIO DE ÁVILA RODRIGUES², GILBERTO FERNANDES CORRÊA ${ }^{3}$, GASPAR HENRIQUE KORNDÖRFER ${ }^{3}$, \\ MARIA AMELIA DOS SANTOS ${ }^{4}$ e LAWRENCE ELLIOT DATNOFF ${ }^{5}$
}

\begin{abstract}
RESUMO - Objetivou-se verificar o efeito da aplicação de silicato de cálcio e da esterilização na supressividade natural de um Latossolo Vermelho-Escuro (LEa) álico textura muito argilosa e na conducividade natural de uma Terra Roxa Estruturada eutrófica (TRe) ao fungo Rhizoctonia solani, em condições de casa de vegetação. Utilizou-se o delineamento inteiramente casualizado em esquema fatorial $2 \times 3 \times 2$. Os fatores foram: duas classes de solo (LEa e TRe - 0-20 cm); três tratamentos (esterilização ou não por autoclavagem, aplicação de silicato e testemunha) e infestação ou não com $R$. solani, com três repetições e 16 plântulas de feijoeiro por parcela. A aplicação de silicato foi feita incorporando $0,63 \mathrm{~g}$ do produto em $1 \mathrm{~kg}$ de cada material de solo, seguido de incubação por 30 dias. Para promover a infestação artificial, foram colocados $800 \mathrm{mg}$ de inóculo em $1 \mathrm{~kg}$ de cada material de solo. O silicato de cálcio aumentou os teores de Ca trocável e a soma de bases nos dois solos. Um decréscimo na saturação por Al de 70 para $19 \%$ e um aumento na saturação por bases de 9 para $21 \%$ alteraram significativamente a supressividade natural do LEa à $R$. solani. Com relação à TRe, a aplicação de silicato não teve nenhum efeito na sua conducividade, dado ao seu natural caráter eutrófico, o qual já é favorável ao desenvolvimento deste fungo. A esterilização não influiu no desenvolvimento de $R$. solani, o que sugere que os fatores abióticos foram os responsáveis pela supressividade ou conducividade desses solos.
\end{abstract}

Termos para indexação: características químicas do solo, solo supressivo, solos tropicais.

\section{INFLUENCE OF CALCIUM SILICATE AND STERILIZATION ON THE NATURAL SUPPRESSIVENESS AND ON THE CONDUCIVENESS OF TWO SOILS TO RHIZOCTONIA SOLANI}

\begin{abstract}
The effect of calcium silicate slag and soil sterilization on the natural suppressiveness of a Typic Acrustox (clay Dark Red Latosol - LEa) and the natural conduciveness of an Oxic Haplustoll (TRe) to Rhizoctonia solani were studied under greenhouse conditions. The experimental design was a three-replicate completely randomized one, with $2 \times 3 \times 2$ factorial combination of the following treatments: two soil kinds (LEa and TRe, collected at 0-20 cm layer); three treatments with and without soil sterilization, calcium silicate slag and nontreated control; and uninfested and infested with $R$. solani. Each soil material was infested previously with $800 \mathrm{mg}$ of the inoculum per $\mathrm{kg}$ soil. Application of silicate was done mixing $0,63 \mathrm{~g}$ of this product with $1 \mathrm{~kg}$ each soil material and incubated for 30 days. The application of silicate increased the exchangeable $\mathrm{Ca}^{2+}$ and bases amount in both soils. The decrease in the aluminum saturation level from 70 to $19 \%$ and the increase in base saturation from 9 to $21 \%$ altered significantly the natural suppressiveness of LEa to R. solani. Application of silicate to the TRe had no effect on its conduciveness, for its natural eutrophic character, which is benefic to $R$. solani development. Sterilization by autoclavation did not influence disease development on bean by $R$. solani. This suggests that possibly other abiotic factors were responsible for either suppressiveness or conduciveness of these soils.

Index terms: soil chemical characteristics, suppressive soil, tropical soils.
\end{abstract}

\footnotetext{
${ }^{1}$ Aceito para publicação em 9 de setembro de 1998.

${ }^{2}$ Eng. Agr., Dep. de Fitopatologia, Universidade Federal de Viçosa (UFV), CEP 36570-000 Viçosa, MG. E-mail: fabricio@alunos.ufv.br

${ }^{3}$ Eng. Agr., Dr., Prof. Titular, Dep. de Agronomia, Universidade
}

Federal de Uberlândia (UFU), Caixa Postal 593, CEP 38400-902 Uberlândia, MG.

${ }^{4}$ Eng ${ }^{\mathrm{a}}$ Agr ${ }^{\mathrm{a}}$, Dre , Prof ${ }^{\mathrm{a}}$ Adjunta, Dep. de Agronomia, UFU.

${ }^{5}$ Eng. Agr., Ph.D., Prof. Associado, University of Florida, Belle Glade, Fl - U.S.A. 8003-33430. 


\section{INTRODUÇÃO}

A rizoctoniose ou podridão-radicular de Rhizoctonia (Rhizoctonia solani Kühn) é uma das doenças radiculares mais comuns do feijoeiro (Phaseolus vulgaris L.) e de maior nocividade no Brasil (Cardoso, 1990). O seu controle é difícil e até mesmo anti-econômico, inviabilizando o plantio do feijoeiro, principalmente em áreas sob pivô central.

Uma das alternativas de controle seria o aproveitamento da supressividade natural a esse patógeno que ocorre em alguns solos. Porém, pouco é o interesse nos dias atuais de se utilizar métodos de controle de doenças que, de algum modo, resultem num menor impacto ambiental. O potencial supressivo a vários patógenos de solo, reduzindo a manifestação de doenças mesmo sob alta densidade de inóculo e condições propícias ao desenvolvimento da doença, acontece em vários solos (Cook \& Baker, 1983).

Alguns fatores físico-químicos do solo, como o $\mathrm{pH}$, atuam na supressividade de alguns solos a certos patógenos radiculares. Porém, quando se trata do mesmo ou de outro patógeno em diferentes solos, este caráter é modificado (Whipps, 1997). O pHé uma característica química muito variável e que se modifica em função de práticas como a calagem e aplicação de adubos acidificantes, os quais podem causar a perda ou a diminuição da supressividade natural de um solo. Chet \& Baker (1980), ao alterarem o pH inicial de um solo de 8,1 para 5,7 e 6,5, observaram uma menor incidência de tombamento causado por $R$. solani em plântulas de alfafa, beterraba e rabanete. Além disso, constataram que o fungo teve um melhor crescimento em meio de cultura com $\mathrm{pH}$ variando de 6,5 a 7,5. Baixos valores de $\mathrm{pH}$ também inibiram a ocorrência do mal-do-pé do trigo e centeio, causada por Gaeumannomyces graminis, principalmente quando se utilizou uma adubação amoniacal (Marschner, 1986). O controle de doenças causadas por outros patógenos de solo, tais como Sclerotium rolfsii e Plasmodiophora brassicae tem sido satisfatório com a aplicação de corretivos (Punja, 1989; Wang \& Hsieh citados por Zambolim \& Ventura, 1993). Altos níveis de Al trocável também estão relacionados com a supressividade natural de alguns solos a $R$. solani (Kobayashi \& Ko, 1985).
A presença de microrganismos antagônicos e competidores aos patógenos de solo permite uma boa sanidade do sistema radicular das plantas ou a manutenção da população destes em níveis não prejudiciais ao hospedeiro, em função de um tamponamento microbiano (Homechin, 1991). Muitos microrganismos são isolados e relacionados com a supressividade de alguns solos (Whipps, 1997). Contudo, um solo biologicamente supressivo provavelmente não poderá ser explicado em termos de um único antagonista (Reis, 1991).

O tratamento do solo com brometo de metila ou calor poderá destruir a supressividade natural do solo (Scher \& Baker, 1980; Kao \& Ko, 1983), pois o efeito na população microbiana é alterado. Pozzer \& Cardoso (1990) observaram que a autoclavagem reduziu a supressividade inicial de um Latossolo Vermelho-Escuro a $R$. solani, porém não teve nenhuma influência na incidência da doença num solo orgânico, que era condutivo. Meyer \& Shew, Ko, citados por Whipps (1997), observaram que a supressividade de alguns solos aos fungos Thielaviopsis basicola e Phytophthora capsici não foi afetada pela autoclavagem, o que sugere que os fatores físico-químicos sozinhos foram a causa desse comportamento.

O presente trabalho teve como objetivo verificar o efeito da aplicação do silicato de cálcio e da autoclavagem em duas classes de solo, na supressividade ou conducividade à Rhizoctonia solani.

\section{MATERIAL E MÉTODOS}

Este experimento foi instalado e conduzido em condições de casa de vegetação pertencente ao Departamento de Agronomia da Universidade Federal de Uberlândia, no período de setembro a dezembro de 1996.

As duas classes de solo utilizadas foram: Latossolo Vermelho-Escuro álico (LEa) e Terra Roxa Estruturada eutrófica (TRe), amostradas na profundidade de $0-20 \mathrm{~cm}$, de textura muito argilosa e respectivamente supressiva e condutiva a Rhizoctonia solani, conforme estudos anteriores.

O isolado de $R$. solani foi obtido de plântulas de feijoeiro exibindo sintomas típicos de podridão-radicular. Cinqüenta discos de micélio com $2 \mathrm{~cm}$ de diâmetro foram retirados de placas-de-petri contendo culturas do patógeno em meio 
de batata-dextrose-ágar (BDA) com duas semanas de idade, e transferidos para um Erlenmeyer contendo um substrato composto por $300 \mathrm{~g}$ de grãos de arroz sem casca, previamente autoclavado a $120^{\circ} \mathrm{C}$ e 1 atm, durante 30 minutos. A incubação ocorreu durante seis dias, em condição ambiente, com agitação diária.

$\mathrm{O}$ delineamento experimental utilizado foi o inteiramente casualizado, num esquema fatorial $2 \times 3 \times 2$, com três repetições, e 16 plântulas de feijoeiro (cultivar Carioca, com sementes de alto vigor) por parcela. Os fatores estudados foram: (a) duas classes de solo; (b) tratamentos dos solos com esterilização por autoclavagem, aplicação de silicato de cálcio e testemunha (sem esterilização e aplicação de silicato); e (c) inoculação ou não de $R$. solani.

O silicato de cálcio (Wollastonita - $\mathrm{CaSiO}_{3}$ ) foi fornecido pela Ipiranga Química de São Paulo, possuindo 24,2\% de silício e 30,1\% de cálcio. A aplicação foi feita através da incorporação de $0,63 \mathrm{~g}$ do produto em $1 \mathrm{~kg}$ de cada material de solo, com posterior incubação por um período de 30 dias antes do início do experimento, para que houvesse uma reação do mesmo com o solo. Parte de cada material de solo foi autoclavado 5 horas antes da montagem do experimento, nas condições de $120^{\circ} \mathrm{C}$ por um período de 30 minutos.

As amostras de cada material de solo foram caracterizadas quanto à textura e submetidas às análises químicas usualmente empregadas para caracterização da fertilidade, seguindo metodologias preconizadas pela Embrapa (1979), antes e após a aplicação do silicato de cálcio (Tabela 1).

A infestação artificial foi feita incorporando-se $800 \mathrm{mg}$ de grãos de arroz pré-colonizados por $R$. solani em $1 \mathrm{~kg}$ de cada material de solo previamente homogeneizado. Avaliou-se o desenvolvimento da doença no 15o dia após a germinação, utilizando-se uma escala de notas variando de 0 a 5 , onde: $0=$ plantas sadias; $1=$ lesões menores ou iguais a $2,5 \mathrm{~mm} ; 2=$ lesões entre 2,5 e $5 \mathrm{~mm} ; 3=$ lesões envolvendo o coleto e causando o sintoma de murcha das folhas; $4=$ planta tombada e/ou morta e $5=$ sementes não germinadas ou plântulas não emergidas. Posteriormente, calculou-se o índice de doença (ID\%), segundo Tinline et al., citados por Noronha et al. (1995), onde:

ID $(\%)=\frac{\sum\left(\text { valor da nota } \times \mathrm{n}^{\mathrm{o}} \text { de plantas com esta nota }\right)}{\left(\mathrm{n}^{\mathrm{o}} \text { total de plantas } \mathrm{x} \text { valor máximo da escala de notas }\right)} \times 100$.

\section{RESULTADOS E DISCUSSÃO}

Através da variável ID encontraram-se diferenças significativas pelo teste $\mathrm{F}(\mathrm{P} \leq 0,05)$ para os fatores: classes de solo, tratamentos (esterilização por autoclavagem, aplicação de silicato de cálcio e testemunha) e inoculação, bem como para as interações duplas: classes de solo x inoculação e classes de solo x tratamentos.

Observou-se diferença significativa no ID entre plântulas de feijoeiro em cada classe de solo, sob condições naturais e artificiais de inoculação (Tabela 2). Sob condição de infestação artificial, o maior ID ocorreu na TRe, a qual diferiu significativamente do ID no LEa, confirmando o caráter supressivo do LEa e conducivo da TRe à Rhizoctonia solani, conforme estudos anteriores.

Após a aplicação do silicato de cálcio nos dois materiais de solo, houve um incremento nos teores de cálcio trocável, indicando ter havido solubilização da fonte de cálcio. No LEa, houve uma redução de $70 \%$ para $19 \%$ na saturação por $\mathrm{Al}$ e um aumento de $9 \%$ para $21 \%$ na saturação por bases (Tabela 1 ).

TABELA 1. Características químicas de duas classes de solo $(0-20 \mathrm{~cm})$ utilizadas para verificar o efeito da aplicação de silicato de cálcio e da autoclavagem na supressividade ou conducividade à Rhizoctonia solani em feijoeiro.

\begin{tabular}{|c|c|c|c|c|c|c|c|c|c|}
\hline \multirow{2}{*}{\multicolumn{3}{|c|}{$\begin{array}{c}\text { Características } \\
\text { das classes de solo }\end{array}$}} & \multicolumn{7}{|c|}{ Análise química ${ }^{2}$} \\
\hline & & & \multirow{2}{*}{$\begin{array}{c}\mathrm{pH} \\
\mathrm{CaCl}_{2} \\
\end{array}$} & \multirow{2}{*}{ Al } & \multirow{2}{*}{\multicolumn{2}{|c|}{$\begin{array}{l}\mathrm{Ca} \\
-\left(\mathrm{cmol}_{\mathrm{c}} / \mathrm{dm}^{3}\right)---\end{array}$}} & \multirow{2}{*}{$\mathrm{T}$} & \multirow{2}{*}{$\mathrm{V}$} & \multirow{2}{*}{$\mathrm{m}$} \\
\hline Veg. & Solo & Fert. & & & & & & & \\
\hline \multirow[t]{2}{*}{$\mathrm{F}$} & $\mathrm{TRe}$ & 1 & 4,7 & 0 & 165 & 201 & 226 & 89 & 0 \\
\hline & & 2 & 5,3 & 0 & 200 & 232 & 268 & 87 & 0 \\
\hline \multirow[t]{2}{*}{$\mathrm{C}$} & $\mathrm{LEa}$ & 1 & 4,0 & 7 & 1 & 3 & 35 & 9 & 70 \\
\hline & & 2 & 4,2 & 3 & 9 & 13 & 63 & 21 & 19 \\
\hline
\end{tabular}

${ }^{1}$ F: vegetação de floresta; C: vegetação de cerrado; fertilidade 1: natural; fertilidade 2: após aplicação de silicato de cálcio.

2 S: soma de bases; T: CTC a pH 7,0; V: saturação por bases; m: saturação por Al. 
Segundo Savant et al. (1997), o silicato de cálcio reduz a toxidez causada por alumínio, ferro e manganês nos solos ácidos e aumenta o teor de cálcio. Com a aplicação do silicato no LEa, o ID aumentou e diferiu significativamente da testemunha (Tabela 3). Esse aumento pode ser explicado em função da mudança nos padrões de fertilidade deste solo, de álica (saturação por alumínio igual ou superior a 50\%) para eutrófica (saturação por bases superior a 50\%), diminuindo a saturação por $\mathrm{Al}$, favorável ao desenvolvimento de $R$. solani no solo. De acordo com Kobayashi \& Ko (1985), altos níveis de Al trocável no solo desfavoreceram o estabelecimento de $R$. solani e estão relacionados com a sua supressividade.

TABELA 2. Efeito de duas classes de solo sob infestação natural e artificial com Rhizoctonia solani no índice de doença em plântulas de feijoeiro ${ }^{1}$.

\begin{tabular}{lcc}
\hline Classes de & \multicolumn{2}{c}{ Infestação } \\
\cline { 2 - 3 } solo & Natural & Artificial \\
\hline LEa & $0,5 \mathrm{aA}$ & $11,1 \mathrm{aB}$ \\
TRe & $1,0 \mathrm{aA}$ & $46,5 \mathrm{bB}$ \\
\hline C.V. $(\%)$ & \multicolumn{3}{c}{24,72} \\
\hline
\end{tabular}

${ }^{1}$ Médias seguidas pela mesma letra minúscula na vertical e pela mesma letra maiúscula na horizontal não diferem entre si, pelo teste de Tukey a $5 \%$ de probabilidade.

TABELA 3. Efeito da aplicação de silicato de cálcio, esterilização e controle em duas classes de solo sobre o índice de doença em plântulas de feijoeiro ${ }^{1}$.

\begin{tabular}{|c|c|c|}
\hline \multirow[t]{2}{*}{ Tratamento } & \multicolumn{2}{|c|}{ Índice de doença (ID\%) } \\
\hline & $\mathrm{LEa}$ & $\mathrm{TRe}$ \\
\hline Silicato de cálcio & $7,9 \mathrm{aA}$ & $13,4 \mathrm{aA}$ \\
\hline Autoclavagem & 3,2abA & $19,2 \mathrm{aB}$ \\
\hline Testemunha & $1,4 \mathrm{bA}$ & $17,7 \mathrm{aB}$ \\
\hline C.V. $(\%)$ & \multicolumn{2}{|c|}{24,72} \\
\hline
\end{tabular}

${ }^{1}$ Médias seguidas pela mesma letra minúscula na vertical e pela mesma letra maiúscula na horizontal não diferem entre si, pelo teste de Tukey a $5 \%$ de probabilidade.

Pesq. agropec. bras., Brasília, v.34, n.8, p.1367-1371, ago. 1999
Na TRe, não houve diferença significativa entre a aplicação de silicato de cálcio e a testemunha, pelo fato de o solo já ser de natureza eutrófica e naturalmente condutivo a $R$. solani. Diferenças significativas entre as duas classes de solo somente ocorreram para a autoclavagem e a testemunha, observando-se maiores ID na TRe (Tabela 3 ).

A aplicação de silicato de cálcio, embora tenha alterado os valores de saturação por bases e por $\mathrm{Al}$, teve pouca influência no $\mathrm{pH}_{\mathrm{CaCl}_{2}}$ (Tabela 1). Esta característica química, no entanto, não explica a perda da supressividade do LEa e nem a manutenção da conducividade da TRe, na qual observou-se maior variação do $\mathrm{pH}_{\mathrm{CaCl}_{2}}$.

Após autoclavagem, o ID aumentou em 56,3 e $7,8 \%$, respectivamente, no LEa e na TRe, em relação à testemunha, porém sem nenhuma diferença significativa (Tabela 3). Tal fato indica que os fatores abióticos, como a saturação por Al e o caráter eutrófico (saturação por bases), foram mais importantes para o efeito supressivo ou conducivo desses solos, que a própria biomassa microbiana. Para outros patógenos, como Fusarium oxysporum f.sp. pisi e Phytophthora cinnamomi, a esterilização eliminou a supressividade natural do solo (Huber \& Schneider, 1984; Baker \& Cook, citados por Reis, 1991).

\section{CONCLUSÕES}

1. Há diminuição na saturação por $\mathrm{Al}$ e aumento nos teores de cálcio trocável e de saturação por bases, pela adição de silicato de cálcio no LEa, reduzindo a sua supressividade natural a Rhizoctonia solani.

2. A aplicação de silicato de cálcio não altera a conducividade natural da TRe.

3. A autoclavagem do LEa e da TRe não influi na supressividade ou conducividade desses solos, o que indica que os fatores físico-químicos são mais importantes para a ocorrência de tais fenômenos.

\section{REFERÊNCIAS}

CARDOSO, J.E. Doenças do feijoeiro causadas por patógenos de solo. Goiânia: Embrapa-CNPAF, 1990. 30p. (Embrapa-CNPAF. Documentos, 30). 
CHET, I.; BAKER, R. Induction of suppressiveness to Rhizoctonia solani in soil. Phytopathology, v.70, p.994-998, 1980.

COOK, R.J.; BAKER, K.F. The nature and practice of biological control of plant pathogens. St. Paul: The American Phytopathology Society, 1983. 539p.

EMBRAPA. Serviço Nacional de Levantamento e Conservação de Solos (Rio de Janeiro, RJ). Manual de métodos de análise de solo. Rio de Janeiro, 1979. $247 \mathrm{p}$.

HOMECHIN, M. Controle biológico de patógenos do solo. In: BETTIOL, W. (Ed.). Controle biológico de doenças de plantas. Jaguariúna: Embrapa-CNPDA, 1991. p.7-23.

HUBER, D.M.; SCHNEIDER, R.W. The description and occurrence of suppressive soils. In: SCHNEIDER, R.W. (Ed.). Suppressive soil and plant disease. St. Paul: The American Phytopathology Society, 1984. p.1-7.

KAO, D.W.; KO, W.H. Nature of suppression of Pythium splendens in a pasture soil in South Kahala, Hawaii. Phytopathology, v.73, p.1284-1289, 1983.

KOBAYASHI, N.; KO, W.H. Nature of suppression of Rhizoctonia solani in Hawaiian soils. Transactions of the British Mycological Society, London, v.84, p.691-694, 1985.

MARSCHNER, H. Mineral nutrition of higher plants. New York: Academic, 1986. p.369-390.

NORONHA, M.A.; MICHEREFF, S.J.; MARIANO, R.L.R. Efeito do tratamento de sementes de caupi com Bacillus subtilis no controle de Rhizoctonia solani. Fitopatologia Brasileira, v.20, p.174-178, 1995.

POZZER, L.; CARDOSO, J.E. Supressividade natural de um Latossolo Vermelho-Escuro a Rhizoctonia solani. Fitopatologia Brasileira, v.15, p.206-210, 1990.

REIS, E.M. Solos supressivos e seu aproveitamento no controle de doenças de plantas. In: BETTIOL, W. (Ed.). Controle biológico de doenças de plantas Jaguariúna: Embrapa-CNPDA, 1991. p.181-193.

PUNJA, Z.K. Influence of nitrogen and calcium compounds on development of disease due to Sclerotium rolfsii. In: ENGELHARD, A.W. (Ed.). Soilborne plant pathogens: Management of diseases with macro and microelements. St. Paul: The American Phytopathology Society, 1989. p.75-89.

SAVANT, N.K.; SNYDER, G.H.; DATNOFF, L.E. Silicon management and sustainable rice production. Advances in Agronomy, v.58, p.151-199, 1997.

SCHER, F.M.; BAKER, R. Mechanism of biological control in a Fusarium suppressive soil. Phytopathology, v.70, p.412-417, 1980.

WHIPPS, J.M. Developments in the biological control of soilborne plant pathogens. In: CALLOW, J.A. (Ed.) Advances in botanical research. Birmingham: Academic, 1997. v.26, p.1-84.

ZAMBOLIM, L.; VENTURA, J.A. Resistência a doenças induzida pela nutrição mineral das plantas. In: FERNANDES, J.M.; PRESTES, A.M.; PICININI, E.C. (Eds.). Revisão anual de patologia de plantas. Passo Fundo: Embrapa-CNPT, 1993. v.1, p.275318. 